\title{
Detailed investigations of proximal tubular function in Imerslund-Gräsbeck syndrome
}

Tina Storm', Christina Zeitz 2,3,4, Olivier Cases ${ }^{2,3,4}$, Sabine Amsellem²,3,4, Pierre J Verroust ${ }^{1,2,3,4}$, Mette Madsen', Jean-François Benoist ${ }^{6}$, Sandrine Passemard ${ }^{7,8}$, Sophie Lebon ${ }^{8}$, Iben Møller Jønsson ${ }^{9}$, Francesco Emma ${ }^{10}$, Heidi Kolds $\varnothing^{11}$, Jens Michael Hertz ${ }^{12}$, Rikke Nielsen ${ }^{1}$, Erik I Christensen ${ }^{1 *}$ and Renata Kozyraki ${ }^{2,3,4,5^{*}}$

\begin{abstract}
Background: Imerslund-Gräsbeck Syndrome (IGS) is a rare genetic disorder characterised by juvenile megaloblastic anaemia. IGS is caused by mutations in either of the genes encoding the intestinal intrinsic factor-vitamin $B_{12}$ receptor complex, cubam. The cubam receptor proteins cubilin and amnionless are both expressed in the small intestine as well as the proximal tubules of the kidney and exhibit an interdependent relationship for post-translational processing and trafficking. In the proximal tubules cubilin is involved in the reabsorption of several filtered plasma proteins including vitamin carriers and lipoproteins. Consistent with this, low-molecular-weight proteinuria has been observed in most patients with IGS. The aim of this study was to characterise novel disease-causing mutations and correlate novel and previously reported mutations with the presence of low-molecular-weight proteinuria.
\end{abstract}

Methods: Genetic screening was performed by direct sequencing of the CUBN and AMN genes and novel identified mutations were characterised by in silico and/or in vitro investigations. Urinary protein excretion was analysed by immunoblotting and high-resolution gel electrophoresis of collected urines from patients and healthy controls to determine renal phenotype.

Results: Genetic characterisation of nine IGS patients identified two novel AMN frameshift mutations alongside a frequently reported AMN splice site mutation and two CUBN missense mutations; one novel and one previously reported in Finnish patients. The novel $A M N$ mutations were predicted to result in functionally null AMN alleles with no cell-surface expression of cubilin. Also, the novel CUBN missense mutation was predicted to affect structural integrity of the IF- $B_{12}$ binding site of cubilin and hereby most likely cubilin cell-surface expression. Analysis of urinary protein excretion in the patients and 20 healthy controls revealed increased urinary excretion of cubilin ligands including apolipoprotein A-I, transferrin, vitamin D-binding protein, and albumin. This was, however, only observed in patients where plasma membrane expression of cubilin was predicted to be perturbed.

Conclusions: In the present study, mutational characterisation of nine IGS patients coupled with analyses of urinary protein excretion provide additional evidence for a correlation between mutation type and presence of the characteristic low-molecular-weight proteinuria.

Keywords: Imerslund-Gräsbeck syndrome, Cubilin, Amnionless, Proximal tubules, Tubular proteinuria

\footnotetext{
* Correspondence: eic@ana.au.dk; renata.kozyraki@inserm.fr

'Department of Biomedicine, Aarhus University, Aarhus, Denmark

${ }^{2}$ INSERM UMR S968, Institut de la Vision, Paris 75012, France

Full list of author information is available at the end of the article
} 


\section{Background}

Imerslund-Gräsbeck Syndrome or Megaloblastic Anaemia 1 (IGS or MGA1, OMIM \#261100) is a rare, autosomal recessive disorder characterised by selective intestinal vitamin $B_{12}$ malabsorption [1,2]. Most common clinical features of the syndrome include megaloblastic anaemia, failure to thrive, recurrent infections and selective lowmolecular-weight proteinuria [3]. IGS is a heterogenic disorder caused by mutations in $C U B N$ or $A M N$ [4,5]. It was originally described simultaneously in Norway and Finland in 1960 [1,2] and since then, several hundred cases have been reported worldwide [6]. A number of these cases, however, may very likely represent misdiagnosed patients suffering from mutations of the gastric intrinsic factor gene (GIF) [7]. Both disorders, IGS and hereditary GIF dysfunction, result in vitamin $\mathrm{B}_{12}$ deficiency and are clinically very difficult to distinguish [6]. Especially, has the diagnosis of a group of IGS patients presenting without proteinuria proved challenging to tell apart from patients with juvenile dysfunction of GIF. Until recently, these patients were clinically distinguished on the basis of the so-called Schillings test [8] revealing any deficiency in functional intrinsic factor. However, the test is no longer available and the two groups of patients may today only be correctly diagnosed through genetic analyses of the genes involved [6].

CUBN is located on chromosome 10 and encodes cubilin (Figure 1B), also known as the intrinsic factorvitamin $\mathrm{B}_{12}\left(\right.$ IF- $\left.\mathrm{B}_{12}\right)$ receptor $[9,10]$ whereas $A M N$ maps to chromosome 14 and encodes amnionless (Figure $1 \mathrm{~B}$ ), a $50 \mathrm{kDa}$, type 1 transmembrane protein [11]. Cubilin is a $460 \mathrm{kDa}$ membrane-associated receptor protein comprising multiple ligand-binding CUB (Complement subcomponents C1r/s, Uegf, and Bmp 1) domains [12,13]. Together, cubilin and amnionless constitute the receptor complex cubam, responsible for intestinal IF- $\mathrm{B}_{12}$ uptake [14]. The IF- $B_{12}$ binding site has been located to cubilin CUB domains 5-8 [15] and recently the structural basis for the interaction was established [16].

We and others have demonstrated a highly interdependent relationship of cubilin and amnionless for correct processing and apical trafficking to the plasma membrane [14,17-24]. So far, no transmembrane segment or endocytic signals have been identified in cubilin [12]. Amnionless however, harbours signals for receptor-mediated endocytosis through clathrin-coated vesicles [14] and may mediate internalization of the intestinal IF- $\mathrm{B}_{12}$ receptor complex by engaging the clathrin-associated sorting proteins disabled-2 (Dab2) and autosomal recessive hypercholesterolemia (ARH) [25]. Cubilin and amnionless are both highly expressed in the small intestine as well as the proximal tubules of the kidney. In the latter, they functionally interact with the multi-specific endocytic receptor megalin allowing the reabsorption of a panel of filtered plasma proteins [26]. Cubilin is particularly important for the normal tubular reabsorption of albumin [27,28], vitamin D-binding protein (VDBP) [29,30], apolipoprotein A-I (apo A-I) [31], and transferrin [32] but only the binding of albumin has been mapped to cubilin so far [33].

Several $C U B N$ and $A M N$ mutations have been reported $[24,34,35]$ since IGS was first reported in the 1960's. Most reported mutations of the $A M N$ gene most

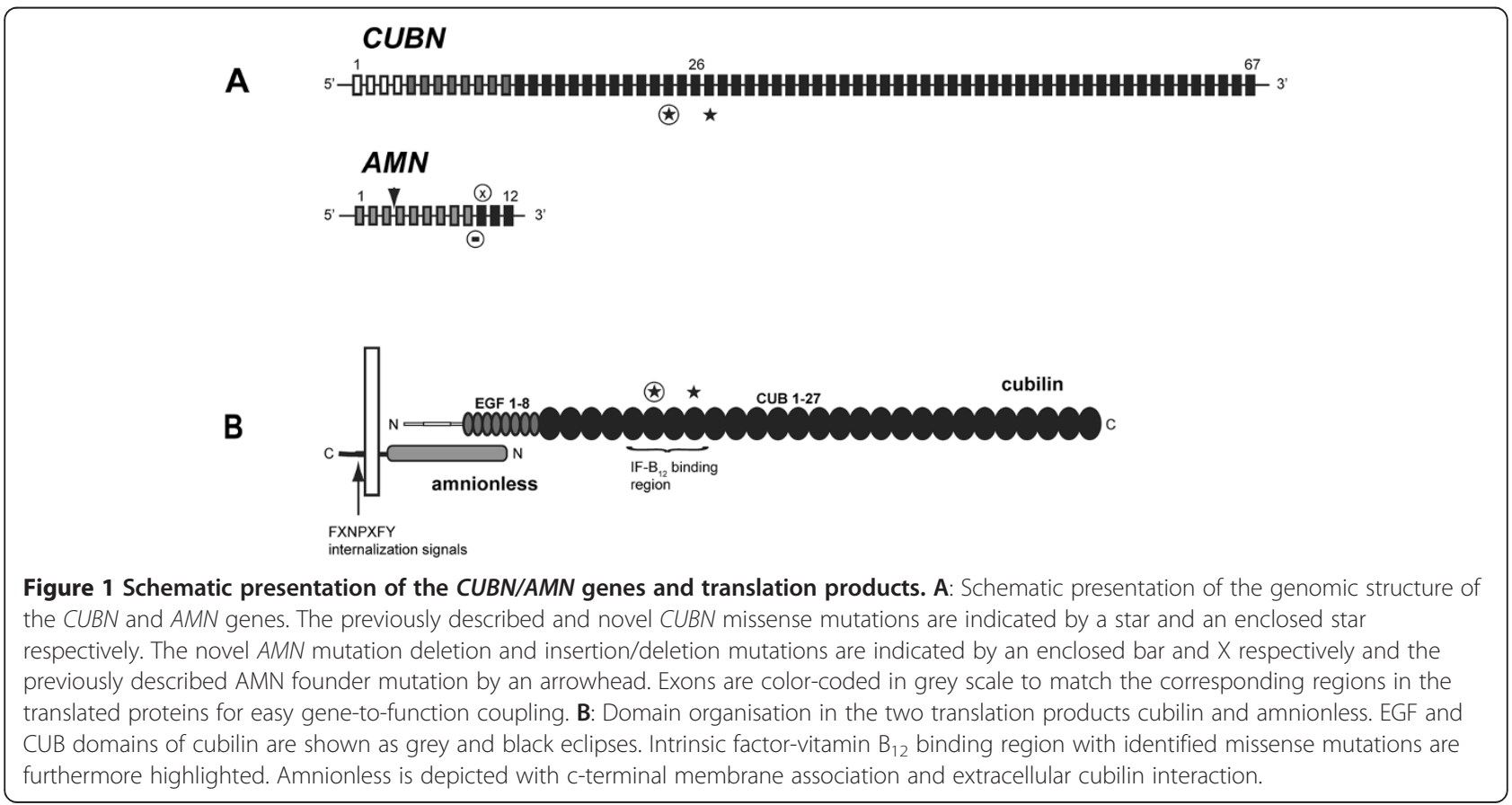


likely represents functional null mutations. One splicesite mutation in particular has been reported a number of times in the Mediterranean region [5,36-38]. This mutation changes the acceptor splice site of $A M N$ intron 3 (c.208-2A>G) and causes skipping of exon 4, resulting in a frameshift and premature stop codon in exon 6 [5]. Based on the established interdependent relationship of cubilin and amnionless the $A M N$ intron 3 mutation most likely affects processing and trafficking of cubilin although this remains to be demonstrated.

Investigations of a canine IGS model have furthermore provided valuable insight into the role of amnionless in this syndrome [20]. The IGS dogs suffer from functional null mutations of the canine homologue to human $A M N$. Immunohistochemical investigations of renal tissue from these dogs showed that cubilin was not expressed at the surface but retained in intracellular vesicles [20]. This clearly illustrates a vital role of amnionless in normal cubilin trafficking and membrane expression and furthermore links mutations of $A M N$ with intestinal malabsorption of IF- $B_{12}$.

The most prevalent mutation found in Finnish patients (FM1) is a CUBN missense mutation changing the highly conserved proline 1297 of cubilin CUB domain 8 to a leucine [4]. This substitution results in decreased affinity of the IF- $\mathrm{B}_{12}$ complex [39] hereby linking the underlying genetic mutation with the intestinal malabsorption of IF- $\mathrm{B}_{12}$ in these patients. In addition, a number of sporadic CUBN null and missense mutations have also been identified $[23,34,35]$. However, the functional implications have only been reported in two patients. A single cytosine for guanine exchange in CUBN intron 23 (c.3330-439C $>\mathrm{G}$, originally described as IVS-intra CUB6 C>G, FM2) was found to trigger complex splicing, resulting in premature truncation of the receptor protein [4]. In addition, we recently investigated another sporadic CUBN mutation in an Italian family [23]. The mutation changed the highly conserved donor splice site of exon 23 most likely resulting in aberrant splicing and functionally null CUBN alleles. Accordingly, no cubilin was detected in renal tissue from this patient [23].

Recently, we established that the molecular background for the low-molecular-weight proteinuria observed in these patients is due to proximal tubular dysfunction of cubilin [23]. Immunohistochemical investigations of renal tissue from a cubilin-deficient patient revealed an abnormal distribution of the receptor partner amnionless as well as reduced uptake of the selective cubilin ligand apo A-I. Furthermore, analyses of the urinary protein excretion in this patient revealed increased urinary excretion of the cubilin ligands transferrin, apo A-I, VDBP, and albumin as previously reported $[28,30-32,40]$. Consistent with observations from the dogs suffering from mutations of the canine $A M N$ homologue, low-molecular-weight proteinuria has also been reported in IGS patients with $A M N$ mutations [24,36-38].

Interestingly, the characteristic low-molecular-weight proteinuria has not been consistently observed in IGS patients [40]. Correlation between the specific diseasecausing mutations and the low-molecular-weight proteinuria has not been established so far but accumulating evidence indicates that functional null mutations of both $C U B N$ and $A M N$ may result in low-molecular-weight proteinuria contrasting observations from patients with the FM1 missense mutation [24,36-38,40].

In the present study, genetic screening of nine IGS patients identified two previously described diseasecausing mutations as well as three novel mutations, including two $A M N$ null mutations and one $C U B N$ missense mutation. Functional investigations of the novel mutations predicted them to result in dysfunctional membrane expression of cubilin. Low-molecular-weight proteinuria was only identified in patients where cubilin was predicted to be absent from the cell surface, thus, providing additional evidence for a correlation between the nature of the genetic mutations and the characteristic urinary protein excretion observed in most of these patients.

\section{Methods}

\section{Patients}

Informed consent for genetic testing was obtained from all the families included in this study. This study was approved by the Central Denmark Region Committee on Biomedical Research Ethics and conducted in accordance with the Declaration of Helsinki. Genomic DNA was isolated from peripheral blood using standard procedures for direct genomic sequencing of $C U B N$ and $A M N$ genes. Diagnosis of selective intestinal vitamin $B_{12}$ malabsorption (IGS or MGA1) was based on previously established criteria [6]. For detailed patient information see Additional file 1. Family information is given in Table 1.

\section{Mutation analyses}

Nucleotides are numbered according to GenBank accession numbers [NM_001081.3] (CUBN) and [NM_030943.3] $(A M N)$ with +1 corresponding to the A of the ATG translation initiation codon and the initiation codon corresponding to codon 1. CUBN and $A M N$ exons, with flanking intronic regions, were amplified using standard PCR procedures with sequence specific primers (primer sequences are available upon request) and a polymerase (HOT FIREPol DNA polymerase; Solis Biodyne, Estonia). $A M N$ exons were amplified in 7 fragments with addition of the PCR additive S-Solution for amplification of GCrich templates. Amplified products were enzymatically purified (ExoSAP-IT; USB Corporation, Cleveland, Ohio, 
Table 1 Family information

\begin{tabular}{|c|c|c|c|}
\hline Family & $\begin{array}{l}\text { Consanguineous } \\
\text { parents }\end{array}$ & $\begin{array}{l}\text { Ethnic } \\
\text { origin }\end{array}$ & $\begin{array}{l}\text { Number } \\
\text { of affected } \\
\text { children }\end{array}$ \\
\hline \multicolumn{4}{|l|}{$A M N$} \\
\hline \multicolumn{4}{|l|}{ Family 1} \\
\hline c. $208-2 A>G^{A} / c .208-2 A>G^{A}$ & yes & Turkish & 1 \\
\hline \multicolumn{4}{|l|}{ (p.Leu70Alafs) } \\
\hline \multicolumn{4}{|l|}{ Family 2} \\
\hline c. $208-2 A>G^{A} / c .208-2 A>G^{A}$ & yes & Tunesian & 2 \\
\hline \multicolumn{4}{|l|}{ (p.Leu70Alafs) } \\
\hline \multicolumn{4}{|l|}{ Family 3} \\
\hline \multicolumn{4}{|l|}{ c.1006+11_1008del/ } \\
\hline \multicolumn{4}{|l|}{ c.1006+11_1008del } \\
\hline \multicolumn{4}{|l|}{ (p.Glu337Asnfs) } \\
\hline \multicolumn{4}{|l|}{ Family 4} \\
\hline \multicolumn{4}{|l|}{ c.1041_1042delinsCTC/ } \\
\hline \multicolumn{4}{|l|}{ c. $208-2 A>G^{A}$} \\
\hline \multicolumn{4}{|l|}{ (p.Glu348Serfs/p.Leu70Alafs) } \\
\hline \multicolumn{4}{|l|}{ CUBN } \\
\hline \multicolumn{4}{|l|}{ Family 5} \\
\hline c.3335G $>A / c .3335 G>A$ & yes & Tunesian & 2 \\
\hline \multicolumn{4}{|l|}{ (p.Gly1112G/u) } \\
\hline \multicolumn{4}{|l|}{ Family 6} \\
\hline$c .3890 C>T / C .3890 C>T^{B}$ & no & Finnish & 1 \\
\hline (p. Pro1297Leu) & & & \\
\hline
\end{tabular}

Table 1 summarises the families included in the study with identified mutations, family background and number of affected children.

${ }^{A}$ Previously described as c.208-2A>G, skipping of exon 4, fs [5]. ${ }^{\text {BP }}$ reviously described by [4]. Paternal/maternal allele.

USA) and used as template in sequencing reactions (Big Dye Terminator v1.1 Cycle Sequencing Kit; Applied Biosystems, Naerum, Denmark). Sequencing products were purified using pre-soaked Sephadex G50 (GE Healthcare Orsay, France) 96-well multiscreen filter plates (Millipore, Molsheim, France). Purified products were analysed on an automated 48-capillary sequencer (ABI 3730 Genetic analyser; Applied Biosystems, Courtaboeuf, France) and the results interpreted using the SeqScape software (Applied Biosystems). Novel sequence variants were compared to commercially available control alleles (Human random control panels; Health Protection Agency Culture Collections, Salisbury, United Kingdom) to exclude commonly occurring polymorphisms. In silico splicing prediction analyses was performed using the NNSPLICE server (0.9 version) (http://fruitfly.org/seq_tools/splice.html). No additional patient material was available for analyses of $A M N$ splicing.

\section{Established constructs}

The genomic fragments comprising $A M N$ exon 8 to exon 12 (c.782-1327) were amplified through PCR from a healthy control subject and the index patient of family 3 (homozygous for c.1006 + 11_1008del) using the following AMN specific primers; 5' -CCCTCCCGCTAGCA TGGCCGTTGTGTTGCTGACCCA-3' containing the NheI restriction site and an in frame ATG start codon and primer 5'-ATTCCCCTCGAGTCATGACGAAGT AACTGTGGCTGGT-3' containing the Xho I restriction site and an in frame TGA stop codon. Amplification products were cloned into expression vectors (pcDNA $^{\mathrm{Tm}} 3.1(+)$; Invitrogen, Taastrup, Denmark) using NheI-HF ${ }^{\mathrm{TM}}$ and Xho I restriction enzymes (New England Biolabs, Medinova Scientific A/S, Glostrup, Denmark) according to manufacturer's guidelines (wt gAMN8-12 and del gAMN8-12) and subsequently transformed into competent cells (One Shot TOP10; Invitrogen) for propagation. $\mathrm{CHO}-\mathrm{K} 1$ cells were transiently transfected with either wt gAMN8-12 or del gAMN8-12 plasmids in duplicates and total RNA was isolated 48 hours after transfection (RNeasy Mini Kit; Qiagen, Ballerup, Denmark). Splicing was analysed by RT-PCR (OneStep RT-PCR kit; Qiagen) using primers 5'-CACCTTCCTGGGTCTGCC TCAGTACC-3' and 5'-GGCGCCACCAGCAGGACCA GCA-3' according to manufacturer's protocol. cDNA amplification products were cloned into vectors (pCR IITOPO ${ }^{\circ}$ using TOPO TA cloning technique, Invitrogen) according to manufacturers protocol for subsequent sequencing.

The c.3335G>A (p.Gly1112Glu) identified in family 5, was introduced into a previously described fragment of human cubilin, encoding CUB domains 5-8 [39], through site-directed, ligase-independent mutagenesis (SLIM)[41] using the following primers (Ft: 5' -CAGAGATGAAGGC TATGAAAAATCACCATTGCTGGG-3'; Rt: $5^{\prime}$-TCA TAGCCTTCATCTCTGATTTCCAGAAAATCTGTA-3'; Fs: 5'-AAAATCACCATTGCTGGG-3'; Rs: 5'-ATTTC CAGAAAATCTGTA-3'). Whole plasmid amplification was carried out in one reaction using a polymerase (Herculase II fusion polymerase; AH Diagnostics a/s, Aarhus, Denmark) with subsequent digestion of template strands and rehybridisation as previously described [41]. Plasmids were subsequently transformed into competent cells (One Shot TOP10, Invitrogen) for propagation.

\section{Cell propagation and transfection}

$\mathrm{CHO}-\mathrm{K} 1$ cells were grown in HyQ-CCM5 (HyClone, Logan, UT, USA) serum free growth medium containing 100 units $/ \mathrm{ml}$ penicillin and $100 \mu \mathrm{g} / \mathrm{ml}$ streptomycin and transiently transfected with plasmids using the Lipofectamine $^{\mathrm{\tau M}} 2000$ (Invitrogen) according to manufacturer's protocol. 


\section{Preparation of cell lysates and conditioned growth medium}

Growth medium was collected from propagated cells prior to lysis and centrifuged at 2,000 g for $2 \mathrm{~min}$. Supernatant was transferred to a new tube, sample buffer added and concentrated for $50 \mathrm{~min}$ at $95^{\circ} \mathrm{C}$. Cells were washed twice with PBS buffer $\mathrm{pH} 7.4$ and subsequently lysed using a Triton X-100 (Merck, Denmark, Industrial Chemicals \& Pigments, Hellerup, Denmark) and EDTAfree protease inhibitor (Complete; Roche, Hvidovre, Denmark) containing buffer. Cell lysates were centrifuged at 4,000 g for $5 \mathrm{~min}$ and supernatants collected. Growth medium and cell lysates were subsequently analysed using SDS-PAGE and immunoblotting.

\section{Urine analyses}

Urine samples (24-hour urine or spot urine) obtained from the patients were frozen at $-80^{\circ} \mathrm{C}$ after collection. Urinary protein excretion was normalised using urinary creatinine concentrations and compared with urines collected from 20 young, healthy subjects (aged 37 years). The urinary excretion of a certain ligand was defined as increased when all of the controls despite variability had excretion levels below the excretion levels observed in patients. Urinary protein excretion was evaluated through immunoblotting or using the Sebia High-Resolution Gel Electrophoresis System (Sebia, Evry, France) according to the manufacturer's instructions. Urine samples were applied on high resolution gels for urine analysis (Hydragel 5 proteinuria; Sebia) and processed using the Hydrasys 2 instrument (Sebia).

\section{Immunoblotting}

Proteins were separated by SDS-PAGE and transferred to an ImmobilonTM-FL PVDF transfer membrane
(Millipore, Copenhagen, Denmark) using the iBlot ${ }^{\mathrm{TM}}$ Dry Blotting System (Invitrogen). Membranes were subsequently blocked and incubated with primary and fluorophore-coupled secondary antibodies according to manufacturer's instructions (LI-COR Biosciences, Cambridge, United Kingdom). Proteins were detected using the Odyssey ${ }^{\text {тм }}$ infrared imager (LI-COR Biosciences).

\section{Antibodies}

(Primary) rabbit anti vitamin D-binding protein (Dako, Glostrup, Denmark), rabbit anti transferrin (Dako), rabbit anti apo A-I (Dako), rabbit anti albumin (Dako), rabbit anti $\alpha_{1}-\mathrm{M}$ (Dako), rabbit anti retinol-binding protein (RBP) (Dako), rabbit anti human cubilin (kindly provided by Søren K. Moestrup, Institute of Biomedicine, Aarhus University, Denmark) (Secondary) goat anti-rabbit IRDye 800 CW (LI-COR Biosciences, Lincoln, Nebraska USA).

\section{Results}

\section{Mutation analyses}

Direct sequencing of the CUBN and $A M N$ genes in six affected families (1-6) (Table 1) revealed two novel mutations of the $A M N$ gene (Family 3 and 4) and one novel mutation of the CUBN gene (Family 5). In families 1 and 2 a homozygous mutation of the $A M N$ intron 3 acceptor splice site was identified (c.208-2A $>$ G). This mutation was originally reported in families of Tunisian Jewish and Turkish origin as c.208-2A>G, skipping of exon 4; fs [5,34] and causes complete skipping of exon 4 resulting in a frameshift and a premature stop codon (Table 2).

In family 3 , direct sequencing revealed a homozygous 70 bp deletion of $A M N$ intron 9 (c.1006+11_1008del) with a resulting elimination of the $A M N$ exon 10 splice acceptor site (Figure 1A) (Table 1). No alternative

Table 2 Functional characterisation of identified IGS causing mutations

\begin{tabular}{|c|c|c|c|c|c|c|c|}
\hline Family & Gene & $\begin{array}{l}\text { Genomic } \\
\text { region }\end{array}$ & $\begin{array}{l}\text { Protein } \\
\text { prediction }\end{array}$ & $\begin{array}{l}\text { Mutation } \\
\text { type }\end{array}$ & Protein region & $\begin{array}{c}\text { Low-molecular-weight } \\
\text { Proteinuria }\end{array}$ & $\begin{array}{l}\text { Predicted cubilin } \\
\text { cell-surface expression }\end{array}$ \\
\hline \multicolumn{8}{|c|}{$A M N$} \\
\hline 1 and 2 & c. $208-2 A>G^{A} / c .208-2 A>G$ & Intron 3 & p.Leu70Alafs & Frameshift & Extracellular domain & Yes $^{*}$ & $\mathrm{No}^{\mathrm{A}}$ \\
\hline 3 & $\begin{array}{l}\text { c.1006+11_1008del/ } \\
\text { c.1006+11_1008del }\end{array}$ & Intron 9 & p.Glu337Asnfs & Frameshift & Extracellular domain & Yes $^{*}$ & $\mathrm{No}^{+}$and \\
\hline 4 & $\begin{array}{c}\text { c.1041_1042delinsCTC/ } \\
\text { c.208- } 2 A>G^{A}\end{array}$ & $\begin{array}{l}\text { Exon 10/ } \\
\text { intron3 }\end{array}$ & $\begin{array}{l}\text { p.Glu348Serfs/ } \\
\text { p.Leu70Alafs }\end{array}$ & $\begin{array}{l}\text { Frameshift/ } \\
\text { Frameshift }\end{array}$ & $\begin{array}{l}\text { Extracellular domain/ } \\
\text { Extracellular domain }\end{array}$ & Yes $^{*}$ & $\mathrm{No}$ \\
\hline \multicolumn{8}{|c|}{ CUBN } \\
\hline 5 & $c .3335 G>A / c .3335 G>A$ & Exon 24 & p.Gly1112Glu & Missense & CUB 6 & Yes $^{*}$ & $\mathrm{No}^{+}$and \\
\hline 6 & C.3890C $>T / C .3890 C>T^{B}$ & Exon 27 & p.Pro1297Leu & Missense & CUB 8 & $(\mathrm{no})^{*}$ & Yes $^{c}$ \\
\hline
\end{tabular}

Table 2 summarises functional characterisation and protein predictions of the identified mutations including mutation classification, observations of lowmolecular-weight proteinuria, prediction of cubilin membrane expression and receptor function. *Based on analyses of urinary excretion of selective cubilin and megalin ligands in patient urines using immunoblotting or high-resolution gel electrophoresis, see Table 3 . ${ }^{\dagger}$ Based on in vitro functional analyses. ${ }^{\circledR}$ Based on in silico protein predictions. ${ }^{A}$ Previously described as c.208-2A>G, skipping of exon $4, f_{s}[5]$. ${ }^{B}$ Previously described by [4]. ${ }^{C}$ Functional analyses previously described by [39]. 


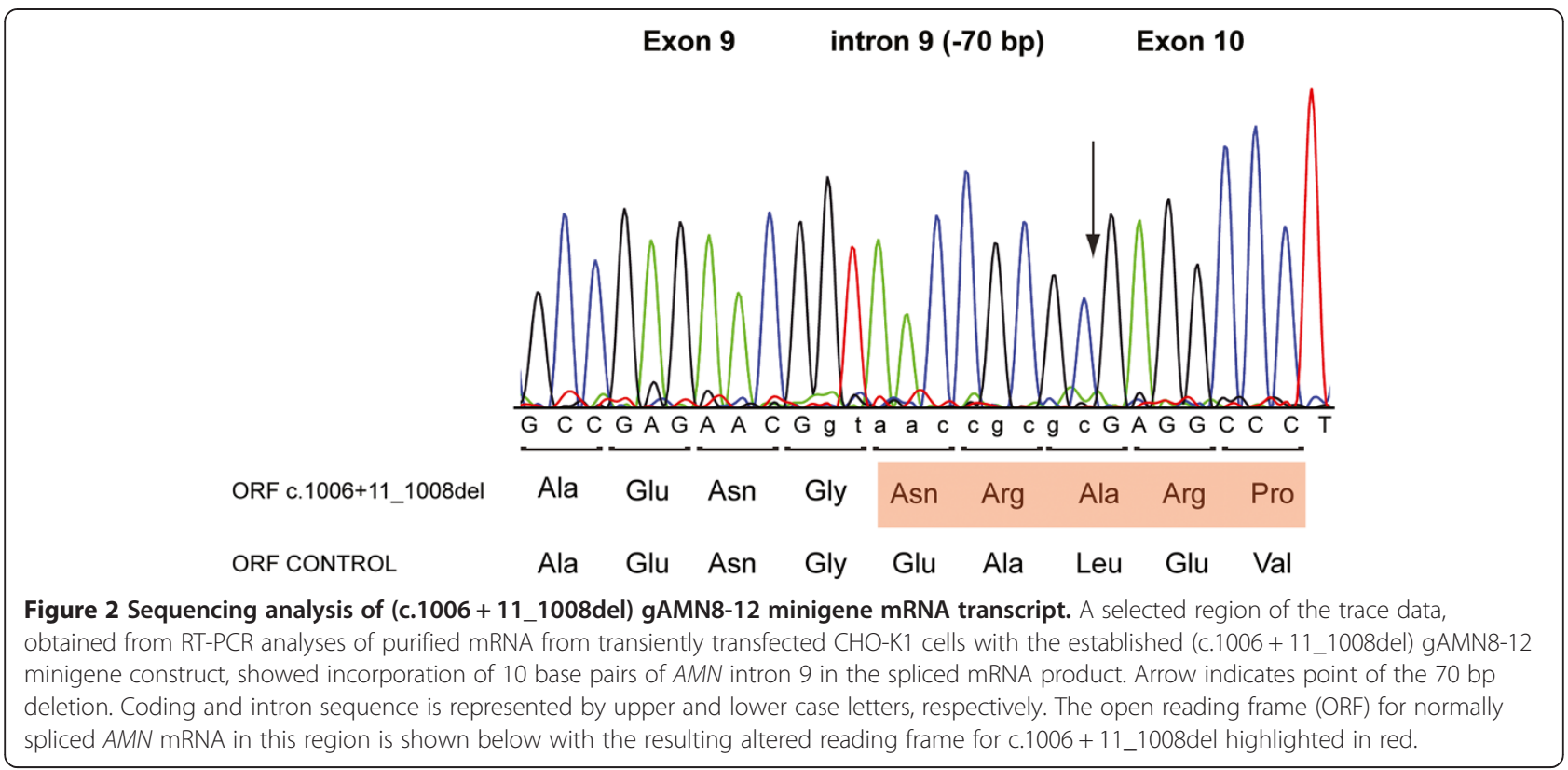

acceptor splice sites could be detected in $A M N$ intron 9 or exon 10 using the NNSPLICE server (0.9 version). RTPCR and cDNA sequencing of total RNA isolated from CHO-K1 cells expressing either genomic wt $A M N$ exon 8-12 or AMN exon 8-12 (c.1006+11_1008del) showed abrogated splicing with retention of the remaining $10 \mathrm{bp}$ of intron 9 in the mutant mRNA transcript (Figure 2). The deletion consequently causes a translational frameshift and a premature stop codon most likely resulting in nonsense mediated decay of the aberrant mRNA and thus functional $A M N$ null alleles (Table 2). Consistent with this, both parents were heterozygous at this position and the 70 bp deletion was not detected in 158 control alleles.

Direct sequencing, of the $A M N$ gene in family 4, revealed compound heterozygous mutations in the two affected children (Table 1). In both patients the c.208$2 \mathrm{~A}>\mathrm{G}$ mutation, described above, was observed on the maternal allele whereas a novel deletion-insertion of exon 10 (c.1041_1042delinsCTC) was identified on the paternal allele (Figure 1A). The insertion-deletion

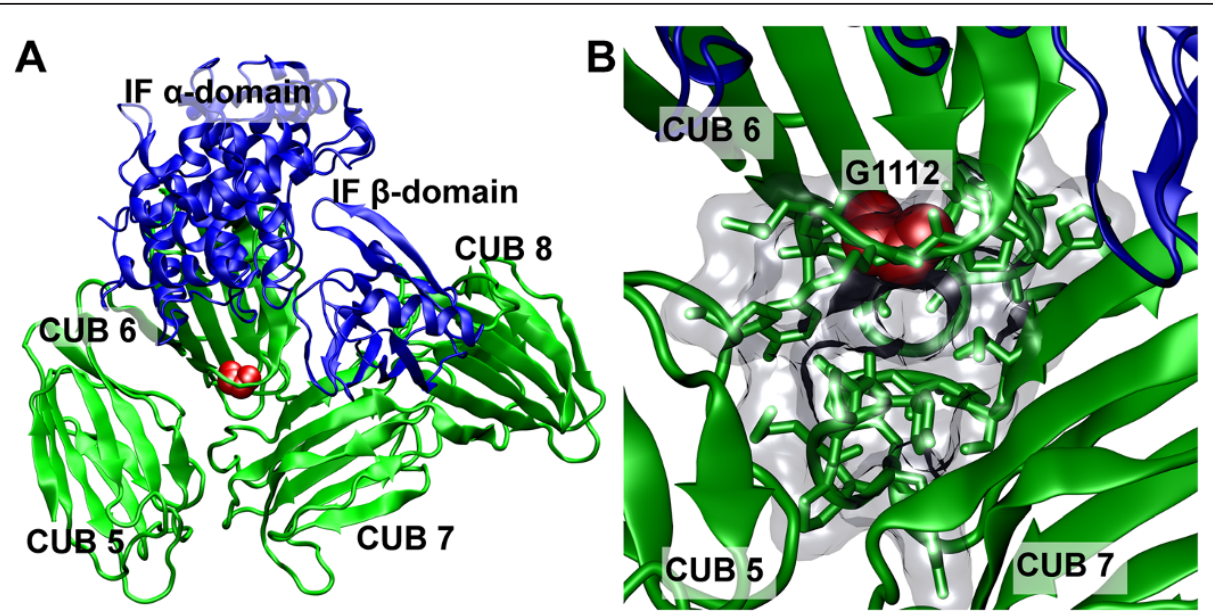

Figure $3 \mathrm{G} 1112$ is located in the tight interface between CUB 5, 6 and 7. A: Overview of the structure of cubilin CUB domains 5-8 in complex with IF (PDB accession 3KQ4) [16]. The CUB domains are illustrated in green cartoons and IF domains in blue cartoons. The G1112 residue is located in the interface between CUB domains 5,6 and 7 and shown as red spheres. B: Zoom-view of the interface between CUB domains 5, 6 and 7. Residues lining the interface are here indicated in green sticks. The space occupied by the interface residues is indicated by a transparent surface. This clearly shows that G1112 is centrally located within the tight interface and accordingly, that a substitution to a larger and polar residue could potentially cause severe sterical clash with surrounding residues as well as disturb inter-domain interactions. The figure was generated using Visual Molecular Dynamics [43]. 
resulted in a translational frameshift and no alternative stop codon could be detected upstream of the AMN 3' UTR region (Table 2). Due to the aberrant and elongated $A M N$ transcript product, the c.1041_1042delinsCTC may result in an unstable amnionless protein and thus in functional null alleles. The mutation was not seen in 166 control alleles.

In family 5, a novel missense mutation of CUBN exon 24 was identified (c.3335G $>$ A, p.G1112E) (Figure 1A and B) (Table 1). CUBN exon 24 partly encodes CUB domain 6 , part of the IF- $B_{12}$ binding site in cubilin $[15,16]$. The mutation changes the fully conserved, small, non-polar residue glycine 1112 to a large, polar glutamate and was not detected in 350 control alleles. Glycine 1112 is located in loop 6 of CUB domain 6 near the interfaces of CUB domains 5, 6 and 7 [16] (Figure 3A and B). The interfaces are here dominated by Van der Waal's interactions indicating that the introduction of a polar glutamate residue in this region could affect the structural integrity of the interacting CUB domains [16]. Consistent with this, introduction of the glutamate residue in this region was found to be probably damaging with a score of 1.0 by PolyPhen2 v2.1 [42].

Cubilin CUB domains 5-8 [39] were expressed in two variants in CHO-K1 cells, a wild-type and a G1112E mutant form. Immunoblotting analyses of conditioned growth medium and cell lysates from $\mathrm{CHO}-\mathrm{K} 1$ cells transiently transfected with wt or G1112E CUB 5-8 showed that the wt CUB 5-8 protein was secreted to the growth medium (Figure 4A) as previously reported [39]. However, the G1112E CUB 5-8 was only observed in cell lysates (Figure 4B) indicating that the mutant cubilin fragment is retained in intracellular compartments. This hereby suggests that the G1112E mutation identified in family 5 may have detrimental effects on the structural integrity of full length cubilin, possibly resulting in impaired processing and decreased or absent cell-surface expression of cubilin. Therefore, intestinal IF- $\mathrm{B}_{12}$-absorption in individuals of family 5 would probably be affected (Table 2).

Finally, direct sequencing revealed a homozygous missense mutation in CUBN exon 27 (c.3890C $>$ T, p. P1297L) in the patient of family 6 (Figure 1B) (Table 1). This mutation has previously been reported in families of Finnish origin [4] and reduces IF- $\mathrm{B}_{12}$ complex recognition by cubilin (Table 2) [39].

\section{Urine analyses}

Immunoblotting or high-resolution gel electrophoresis of urine collected from the patients of families 1-5 showed increased urinary excretion of the cubilin ligands; transferrin, apo A-I, albumin, VDBP, and $\alpha 1$-microglobulin $\left(\alpha_{1}-M\right)$, recently described as a novel ligand of cubilin (Table 3) [23]. In line with a previous report of urinary protein excretion in FM1 patients [40], analyses of urinary

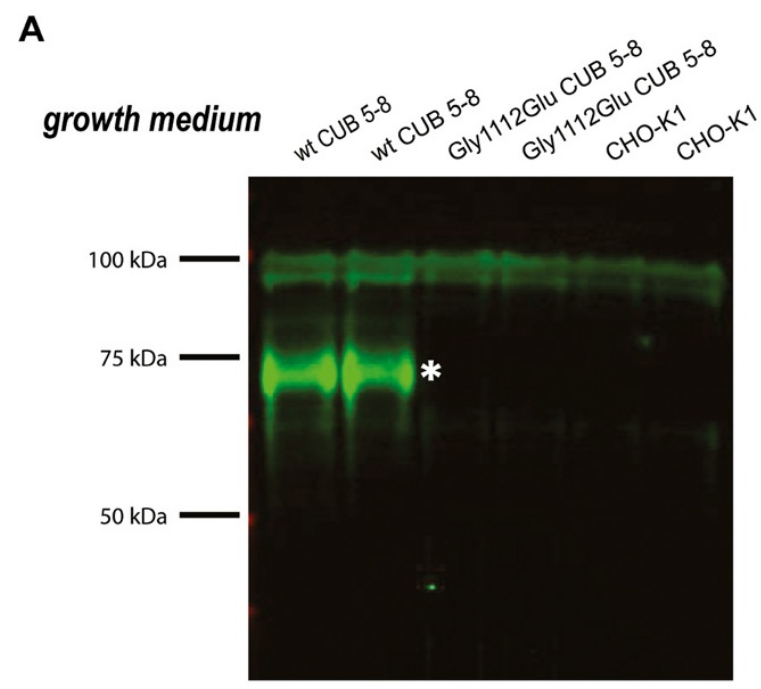

B

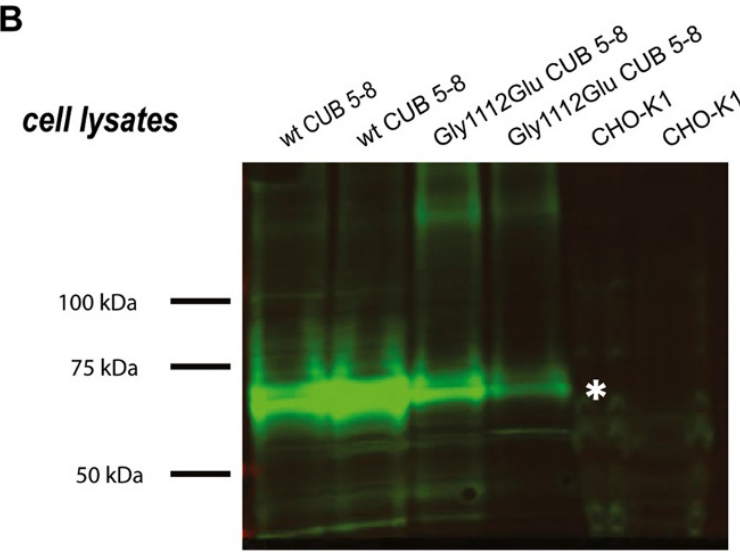

Figure 4 Immunoblotting of conditioned growth medium (A) and cell lysates (B) from CHO-K1 cells transiently transfected with wt or Gly1112Glu CUB 5-8 cubilin. Proteins were separated using SDS-PAGE (3-8\%). and transferred to an Immobilon ${ }^{\mathrm{TM}}-\mathrm{FL}$ PVDF transfer membrane using the iBlot ${ }^{\text {TM }}$ Dry Blotting System. CUB 5-8 proteins were detected with a rabbit anti human cubilin antibody and visualised using LICOR IRDye $\lambda 800$ goat a-rabbit. Immunoreactive bands, consistent with the size of recombinant cubilin CUB 5-8, are indicated with white asterisks. No mutant CUB 5-8 protein was detected in the conditioned growth medium in contrast to the wt CUB 5-8 protein as previously described [39]. Both the wt and mutant protein were detected in cell lysates.

protein excretion in the index patient of family 6 did not show clearly increased urinary excretion of albumin, transferrin or VDBP (Table 3). Also, no increased urinary excretion of the megalin ligand RBP was observed in the patient urines consistent with an isolated tubular cubilin dysfunction.

\section{Discussion}

In the present study, we identified two novel mutations of the $A M N$ gene and one novel mutation of the CUBN gene as well as three previously described disease- 
Table 3 Urinary protein excretion

\begin{tabular}{|c|c|c|c|c|c|c|}
\hline Mutation & Albumin & Transferrin & VDBP & Apo A-I & $a_{1}-M$ & RBP \\
\hline \multicolumn{7}{|l|}{$A M N$} \\
\hline \multicolumn{7}{|l|}{ c. $208-2 A>G / C .208-2 A>G^{A}$} \\
\hline \multicolumn{7}{|l|}{ (p.Leu70Alafs) } \\
\hline \multicolumn{7}{|c|}{ c.1006+11_1008del/c.1006+11_1008del } \\
\hline \multicolumn{7}{|c|}{ (p.Glu337Asnfs) } \\
\hline \multicolumn{7}{|l|}{ c.1041_1042delinsCTC/c.208-2A> $G^{A}$} \\
\hline \multicolumn{7}{|l|}{ (p.Glu348Serfs/p.Leu70Alafs) } \\
\hline \multicolumn{7}{|l|}{ CUBN } \\
\hline \multicolumn{7}{|l|}{$c .3335 G>A / c .3335 G>A$} \\
\hline \multicolumn{7}{|l|}{ (p.Gly1112Glu) } \\
\hline$c .3890 C>T / C .3890 C>T^{B}$ & & & & & & \\
\hline Pro12071 & $(x)$ & $(x)$ & $(x)$ & $(x)$ & $(x)$ & N \\
\hline
\end{tabular}

Table 3 summarises the urinary protein excretion in the six families according to identified mutations. Urines were analysed by immunoblotting or high-resolution gel electrophoresis for urinary protein excretion of the cubilin ligands albumin, transferrin, VDBP, Apo A-l, $a_{1}-M$ as well as a selective ligand of megalin, RBP. Increased urinary excretion of the listed proteins is indicated with an $x$ and with $(x)$ if only trace amounts were observed. No $+x$ indicates that not all the affected patients with this mutation showed similar increased urinary excretion.

${ }^{A}$ Previously described as c.208-2A>G, skipping of exon $4, f s[5] .{ }^{B}$ Previously described by [4].

causing mutations through genetic screening of IGS patients from six families. In addition, we performed a detailed analysis of the urinary protein excretion in these patients and investigated effects on receptor function through in silico and/or in vitro analyses. Table 2 summarises the functional characterisations of the detected mutations.

It was previously proposed that downstream putative transcription start sites of the $A M N$ gene were responsible for the non-lethal phenotype of IGS patients with $A M N$ mutations in the $5^{\prime}$ region [5] in contrast to the embryonic lethality observed in Amn-deficient mice [11]. However, this does not appear to be the case as subsequent reports have identified mutations farther downstream in the $A M N$ gene [34]. Instead, it may represent essential differences in embryonic development of humans and mice [44,45]. Human studies of IGS are therefore crucial for understanding the underlying molecular pathology of the clinical manifestations in these patients. This is, however, very difficult due to lack of accessible cubilin- and amnionless-expressing tissues.

In families 1 and 2 we identified the previously described c.208-2A>G mutation of the $A M N$ gene. Both families originate from the Mediterranean region (Table 1) where this mutation was previously reported a number of times [5,36-38]. Identification of this mutation in additional families hereby provides further evidence of a founder effect originating from this region $[34,46]$. The $70 \mathrm{bp}$ intronic deletion of the $A M N$ gene identified in family 3 is to our knowledge the largest deletion reported in an IGS patient so far and most likely results in functionally null $A M N$ alleles. Compound heterozygous mutations of the $A M N$ gene have not been frequently reported
$[24,35,47,48]$ but here we report an additional case of a compound heterozygous mutation of the $A M N$ gene. In family 4, c.208-2A $>\mathrm{G}$ was identified on the maternal allele whereas a novel deletion-insertion of exon 10 (c.1041_1042delinsCTC) was identified on the paternal allele. To our knowledge, this is also the first report of an insertion-deletion mutation in an IGS patient, thus adding to the heterogeneity of the syndrome. Similar to the $70 \mathrm{bp}$ deletion identified in family 3 , the deletion-insertion most likely results in a functional null $A M N$ allele. Both the previously described Mediterranean founder mutation and the novel $A M N$ mutations most likely affect cell surface expression of cubilin (Table 2), as posttranslational modifications and apical membrane expression of cubilin is highly dependent on proper amnionless function and localisation $[17,18,20,28]$.

Genetic screening of family 5 and 6 revealed two distinct missense mutations of the CUBN gene. Family 6 is of Finnish origin and here, the previously described FM1 mutation was identified in the affected child. In family 5 , however, a novel missense mutation of CUBN exon 24 (c.3335G>A, p. G1112E) was identified. The affected residue is located in CUB domain 6 which is part of the IF- $B_{12}$ binding site of cubilin $[15,16]$. Functional analyses of the G1112E mutation showed intracellular retention of the mutant protein in transfected $\mathrm{CHO}-\mathrm{K} 1$ cells, most likely caused by detrimental effects on structural integrity of the CUB domain interactions (Table 2). Despite the seemingly similar nature of the two CUBN mutations, the functional analyses predict highly distinctive effects on receptor function. This prediction is consistent with the observed differences in urinary protein excretion in the affected patients from the two families 
(Table 3). In line with previous observations, the patient of Finnish origin (FM1, P1297L) did not show a clear increase in urinary excretion of cubilin ligands (Table 3) [40]. Although previous in vitro studies of P1297L suggest that the mutation does not affect the structural integrity of the IF- $B_{12}$ binding site of cubilin [39], limited amounts of cubilin ligands were detected in the urine of this patient. As the interaction sites of very few cubilin ligands have been mapped it is likely that these may have overlapping interaction sites with IF- $\mathrm{B}_{12}$. Thus, this could possibly result in decreased affinity for more cubilin ligands besides IF- $\mathrm{B}_{12}$ and consequently also in a slightly less efficient proximal tubular function of cubilin.

In contrast, increased urinary excretion of the cubilin ligands; albumin, transferrin, VDBP, apo A-I and $\alpha_{1}-\mathrm{M}$ was detected in the patients of family 5 . This is in line with observations from the patient identified with the IVS-intraCUB6 C>G, FM2 CUBN mutation [30-32,40]. Consistent with predictions of disrupted cubilin membrane expression, increased urinary excretion of cubilin ligands was also observed in the patients with $A M N$ mutations (Table 3).

Thus, the observations presented here provide additional evidence supporting a correlation between the nature of the IGS-causing mutation and the presence of low-molecular-weight proteinuria. Combined with previous reports of low-molecular-weight proteinuria in IGS patients $[24,35-38,40]$ this constitutes a solid basis for classifying identified IGS causing mutations as either; 1) mutations affecting only receptor recognition of IF- $\mathrm{B}_{12}$ in the small intestine or 2) mutations of $C U B N$ or $A M N$ affecting the overall expression of cubilin on the cell surface resulting in both intestinal IF- $\mathrm{B}_{12}$ malabsorption and decreased proximal tubular reabsorption of cubilin ligands from the glomerular ultrafiltrate.

Interestingly, Tanner and co-workers did not identify any IGS-causing mutations beyond CUBN exon 28 (corresponding to cubilin CUB domain 8) in a recent large genetic study of families with inherited malabsorption of cobalamin [48]. Furthermore, a recent report described a novel single base pair deletion in CUBN exon 53 (c.8355delA; p.S2785fsX19, corresponding to cubilin CUB domain 20) causing only albuminuria but not megaloblastic anaemia [49]. The functional consequences of this particular exon 53 single base pair deletion were not investigated but a similar mutation was recently reported in a group of border collies affected with IGS [50]. Detailed investigations of the cubilin expression and function in these dogs identified reduced expression of cubilin and no evidence of a stable truncated cubilin protein. The vitamin $B_{12}$ status of the patients harbouring the c.8355delA mutation was not analysed in detail but based on the functional investigations in the dog model, it is likely that the patients are deficient in vitamin $B_{12}$ despite the absence of megaloblastic anaemia. Both patients are under 5 years of age and late onset IGS has been reported multiple times in the literature [3]. Because CUB domains 22-27 bind megalin in vitro [51] and numerous studies have established that megalin is essential for the endocytic function of cubilin in the proximal tubules [52], one might still speculate, however, that $C U B N$ variations in this particular region, resulting in a stable cubilin protein, could constitute a third group of CUBN variations that affects only proximal tubular function of cubilin without affecting the intestinal function. Thus, it may be possible that certain $C U B N$ mutations may lead to a cubilin related proteinuria without causing IGS. However, based on the current available data, this remains purely speculative and clearly, additional research is needed to further elucidate this.

\section{Conclusions}

In conclusion, the data presented here provide novel insight into the molecular mechanisms underlying the pathology of intestinal IF-B $\mathrm{B}_{12}$ malabsorption and low-molecularweight proteinuria of IGS. They furthermore provide additional evidence for a correlation between the nature of the individual disease-causing mutation and the presence of low-molecular-weight proteinuria in IGS patients.

\section{Additional file}

Additional file 1: Clinical data on investigated patients.

\section{Abbreviations}

$a_{1}$-M: a1-Microglobulin; apo A-l: Apolipoprotein A-l; ARH: Autosomal recessive hypercholesterolemia; CUB: Complement subcomponents $\mathrm{C} 1 \mathrm{r} / \mathrm{s}$, Uegf, and Bmp 1; Dab2: Disabled-2; IF-B 12 : Intrinsic factor-vitamin $B_{12}$; IGS: Imersluñ d-Gräsbeck syndrome; MGA1: Megaloblastic anaemia 1; OMIM: Online mendelian inheritance in man; RBP: Retinol-binding protein; SLIM: Site-directed, ligase-independent mutagenesis; VDBP: Vitamin D-binding protein.

\section{Competing interests}

The authors declare that they have no competing interests.

\section{Authors' contributions}

TS was involved in the study design and interpretation of data. TS also performed genetic screening, in silico and in vitro molecular analyses, urinary analyses as well as drafting the manuscript. CZ was involved in genetic screening and bioinformatic interpretation of genetic data. OC was involved in the study design and interpretation of data. SA was involved in genetic screening and urinary analyses. MM was involved in the design and interpretation of molecular analyses of identified mutations. IMJ conducted collection of urine samples from healthy control subjects. HK provided 3D illustrations of crystal structures for interpretation of missense mutations and participated in interpretation of data. J-FB was involved in recruitment and clinical investigation of patients. SP was involved in recruitment and clinical investigation of patients. SL was involved in genetic screening. J-MH was involved in genetic screening and bioinformatic interpretation of genetic data. FE was involved in recruitment and clinical investigation of patients. $\mathrm{RN}, \mathrm{PV}, \mathrm{EIC}$ were involved in study design and interpretation of data as well as finalising the manuscript. RK was involved in study design and interpretation of data as well as finalising the manuscript. All authors read and approved the final version of the manuscript. 


\section{Acknowledgements}

The authors would like to thank the families and clinicians (Dr. Ogier de Baulny and Dr. Deschênes, Robert Debré Hospital, Paris; Dr. Petit, Trousseau Hospital, Paris and Dr. Douillet, Fontainebleau Hospital, France) who participated in this study.

This work was supported in part by the University of Aarhus, the Danish Medical Research Council, the NOVO-Nordisk Foundation, The Lundbeck Foundation, The Danish Kidney Association, Region Viborg, Fondation Voir et Entendre, and the program of the European Community, EUNEFRON (FP7, GA\#201590). We sincerely thank Dr. S.K. Moestrup (Department of Biomedicine, University of Aarhus) for kindly providing the rabbit anti human cubilin antibody and furthermore, Hanne Sidelmann, Pia K. Nielsen, Marie-Elise Lancelot and Damien Latour for skilful technical assistance.

\section{Author details}

'Department of Biomedicine, Aarhus University, Aarhus, Denmark. ${ }^{2}$ INSERM UMR 5968, Institut de la Vision, Paris 75012, France. ${ }^{3}$ UPMC Univ Paris 06, UMR_S 968, Institute de la Vision, Paris F-75012, France. ${ }^{4}$ CNRS, UMR_7210, Paris F-75012, France. ${ }^{5}$ Service de Biochimie B, Hôpital Saint-Antoine, Paris, France. ${ }^{6}$ Laboratoire de Biochimie, Hôpital Robert Debré, Paris, France. ${ }^{7}$ Service de Génétique, Hôpital Robert Debré, Paris, France. ${ }^{8}$ Inserm U676, Hôpital Robert Debré, Paris, France. ${ }^{9}$ Department of Pediatrics, Aarhus University Hospital, Aarhus, Denmark. ${ }^{10}$ Department of Nephrology and Urology, Division of Nephrology and Dialysis, Ospedale Bambino Gesù, IRCCS, Rome, Italy. " Centre for Insoluble Protein Structures (inSPIN) and Interdisciplinary Nanoscience Center (iNANO), Department of Chemistry, Aarhus University, Aarhus, Denmark. ${ }^{12}$ Department of Clinical Genetics, Odense University Hospital, Odense, Denmark.

\section{Received: 16 July 2012 Accepted: 18 October 2013}

Published: 24 October 2013

\section{References}

1. Imerslund O: Idiopathic chronic megaloblastic anemia in children. Acta Paedr Scand 1960, 49:1-115.

2. Grasbeck R, Gordin R, Kantero I, Kuhlback B: Selective vitamin B12 malabsorption and proteinuria in young people. Acta Med Scand 1960, 167:289-296.

3. Grasbeck R: Imerslund-Grasbeck syndrome (selective vitamin B(12) malabsorption with proteinuria). Orphanet J Rare Dis 2006, 1:17.

4. Aminoff M, Carter JE, Chadwick RB, Johnson C, Grasbeck R, Abdelaal MA, Broch $H$, Jenner LB, Verroust PJ, Moestrup SK, et al: Mutations in CUBN, encoding the intrinsic factor-vitamin B12 receptor, cubilin, cause hereditary megaloblastic anaemia 1. Nat Genet 1999, 21:309-313.

5. Tanner SM, Aminoff M, Wright FA, Liyanarachchi S, Kuronen M, Saarinen A, Massika O, Mandel H, Broch H, de la Chapelle A: Amnionless, essential for mouse gastrulation, is mutated in recessive hereditary megaloblastic anemia. Nat Genet 2003, 33:426-429.

6. Grasbeck R, Tanner SM: Juvenile selective vitamin B malabsorption: 50 years after its description-10 years of genetic testing. Pediatr Res 2011, 70:222-228.

7. Tanner SM, Li ZY, Perko JD, Oner C, Cetin M, Altay C, Yurtsever Z, David KL, Faivre L, Ismail EA, et al: Hereditary juvenile cobalamin deficiency caused by mutations in the intrinsic factor gene. Proc Natl Acad Sci USA 2005, 102:4130-4133.

8. Schilling RF: Intrinsic factor studies II. The effect of gastric juice on the urinary excretion of radioactivity after oral administration of radioactive vitamin B12. J Lab Clin Med 1953, 42:860-866.

9. Seetharam B, Christensen El, Moestrup SK, Hammond TG, Verroust PJ: Identification of rat yolk sac target protein of teratogenic antibodies, gp280, as intrinsic factor-cobalamin receptor. J Clin Invest 1997, 99:2317-2322.

10. Seetharam B, Levine JS, Ramasamy M, Alpers DH: Purification, properties, and immunochemical localization of a receptor for intrinsic factor-cobalamin complex in the rat kidney. J Biol Chem 1988, 263:4443-4449.

11. Kalantry S, Manning S, Haub O, Tomihara-Newberger C, Lee HG, Fangman J, Disteche CM, Manova K, Lacy E: The amnionless gene, essential for mouse gastrulation, encodes a visceral-endoderm-specific protein with an extracellular cysteine-rich domain. Nat Genet 2001, 27:412-416.

12. Kozyraki R, Kristiansen M, Silahtaroglu A, Hansen C, Jacobsen C, Tommerup $\mathrm{N}$, Verroust PJ, Moestrup SK: The human intrinsic factor-vitamin B12 receptor, cubilin: molecular characterisation and chromosomal mapping of the gene to $10 \mathrm{p}$ within the autosomal recessive megaloblastic anemia (MGA1) region. Blood 1998, 91:3593-3600.

13. Moestrup SK, Kozyraki R, Kristiansen M, Kaysen JH, Rasmussen HH, Brault D, Pontillon F, Goda FO, Christensen El, Hammond TG, et al: The intrinsic factor-vitamin B12 receptor and target of teratogenic antibodies is a megalin-binding peripheral membrane protein with homology to developmental proteins. J Biol Chem 1998, 273:5235-5242.

14. Fyfe JC, Madsen M, Hojrup P, Christensen El, Tanner SM, de la Chapelle A, He QC, Moestrup SK: The functional cobalamin (vitamin B-12)-intrinsic factor receptor is a novel complex of cubilin and amnionless. Blood 2004, 103:1573-1579.

15. Kristiansen M, Kozyraki R, Jacobsen C, Nexo E, Verroust PJ, Moestrup SK: Molecular dissection of the intrinsic factor-vitamin B12 receptor, cubilin, discloses regions important for membrane association and ligand binding. J Biol Chem 1999, 274:20540-20544.

16. Andersen CB, Madsen M, Storm T, Moestrup SK, Andersen GR: Structural basis for receptor recognition of vitamin-B(12)-intrinsic factor complexes. Nature 2010, 464:445-448.

17. Fyfe JC, Ramanujam KS, Ramaswamy K, Patterson DF, Seetharam B: Defective brush-border expression of intrinsic factor-cobalamin receptor in canine inherited intestinal cobalamin malabsorption. J Biol Chem 1991, 266:4489-4494.

18. Strope S, Rivi R, Metzger T, Manova K, Lacy E: Mouse amnionless, which is required for primitive streak assembly, mediates cell-surface localization and endocytic function of cubilin on visceral endoderm and kidney proximal tubules. Development 2004, 131:4787-4795.

19. Coudroy G, Gburek J, Kozyraki R, Madsen M, Trugnan G, Moestrup SK, Verroust PJ, Maurice M: Contribution of cubilin and amnionless to processing and membrane targeting of cubilin-amnionless complex. J Am Soc Nephrol 2005, 16:2330-2337.

20. He Q, Madsen M, Kilkenney A, Gregory B, Christensen El, Vorum H, Hojrup P, Schaffer AA, Kirkness EF, Tanner SM, et al: Amnionless function is required for cubilin brush-border expression and intrinsic factor-cobalamin (vitamin B12) absorption in vivo. Blood 2005, 106:1447-1453.

21. Smith BT, Mussell JC, Fleming PA, Barth JL, Spyropoulos DD, Cooley MA, Drake CJ, Argraves WS: Targeted disruption of cubilin reveals essential developmental roles in the structure and function of endoderm and in somite formation. BMC Dev Biol 2006, 6:30.

22. Amsellem S, Gburek J, Hamard G, Nielsen R, Willnow TE, Devuyst O, Nexo E, Verroust PJ, Christensen El, Kozyraki R: Cubilin is essential for albumin reabsorption in the renal proximal tubule. J Am Soc Nephrol 2010, 21:1859-1867.

23. Storm T, Emma F, Verroust PJ, Hertz JM, Nielsen R, Christensen El: A patient with cubilin deficiency. N Engl J Med 2011, 364:89-91.

24. Namour F, Dobrovoljski G, Chery C, Audonnet S, Feillet F, Sperl W, Gueant JL: Luminal expression of cubilin is impaired in Imerslund-Grasbeck syndrome with compound $\mathrm{AMN}$ mutations in intron 3 and exon 7. Haematologica 2011, 96:1715-1719.

25. Pedersen GA, Chakraborty S, Steinhauser AL, Traub LM, Madsen M: AMN directs endocytosis of the intrinsic factor-vitamin $B(12)$ receptor cubam by engaging ARH or Dab2. Traffic 2010, 11:706-720.

26. Christensen $E$, Verroust $P$, Nielsen R: Receptor-mediated endocytosis in renal proximal tubule. Pflugers Arch 2009, 458:1039-1048.

27. Cui S, Verroust PJ, Moestrup SK, Christensen El: Megalin/gp330 mediates uptake of albumin in renal proximal tubule. Am J Physiol 1996, 271:F900-F907.

28. Birn H, Fyfe JC, Jacobsen C, Mounier F, Verroust PJ, Orskov H, Willnow TE, Moestrup SK, Christensen El: Cubilin is an albumin binding protein important for renal tubular albumin reabsorption. J Clin Invest 2000, 105:1353-1361.

29. Nykjaer A, Dragun D, Walther D, Vorum H, Jacobsen C, Herz J, Melsen F, Christensen El, Willnow TE: An endocytic pathway essential for renal uptake and activation of the steroid 25-(OH) vitamin D3. Cell 1999, 96:507-515

30. Nykjaer A, Fyfe JC, Kozyraki R, Leheste JR, Jacobsen C, Nielsen MS, Verroust PJ, Aminoff M, de la Chapelle A, Moestrup SK, et al: Cubilin dysfunction causes abnormal metabolism of the steroid hormone $25(\mathrm{OH})$ vitamin D3. Proc Natl Acad Sci USA 2001, 98:13895-13900.

31. Kozyraki R, Fyfe J, Kristiansen M, Gerdes C, Jacobsen C, Cui S, Christensen El, Aminoff M, de la Chapelle A, Krahe R, et al: The intrinsic factor-vitamin B12 
receptor, cubilin, is a high-affinity apolipoprotein A-I receptor facilitating endocytosis of high-density lipoprotein. Nat Med 1999, 5:656-661.

32. Kozyraki R, Fyfe J, Verroust PJ, Jacobsen C, Dautry-Varsat A, Gburek J, Willnow TE, Christensen El, Moestrup SK: Megalin-dependent cubilin-mediated endocytosis is a major pathway for the apical uptake of transferrin in polarized epithelia. Proc Natl Acad Sci USA 2001, 98:12491-12496.

33. Yammani RR, Seetharam S, Seetharam B: Identification and characterisation of two distinct ligand binding regions of Cubilin J Biol Chem 2001, 48:44777-44784.

34. Tanner SM, Li ZY, Bisson R, Acar C, Oner C, Oner R, Cetin M, Abdelaal MA, Ismail EA, Lissens W, et al: Genetically heterogeneous selective intestinal malabsorption of vitamin B-12: founder effects, consanguinity, and high clinical awareness explain aggregations in Scandinavia and the Middle East. Hum Mutat 2004, 23:327-333.

35. Hauck FH, Tanner SM, Henker J, Laass MW: Imerslund-Grasbeck syndrome in a 15-year-old German girl caused by compound heterozygous mutations in CUBN. Eur J Pediatr 2008, 167:671-675.

36. Broides A, Yerushalmi B, Levy R, Hadad N, Kaplun N, Tanner SM, de la Chapelle A, Levy J: Imerslund-Grasbeck syndrome associated with recurrent aphthous stomatitis and defective neutrophil function. J Pediatr Hematol Oncol 2006, 28:715-719.

37. Bouchlaka C, Maktouf C, Mahjoub B, Ayadi A, Tahar Sfar M, Sioud M, Geuddich N, Belhadjali Z, Rebaï A, et al: Genetic heterogegeity of megaloblastic anaemia type 1 in tunisian patients. J Hum Genet 2007, 52:262-270

38. Levin-laina N, Dinour D, Morduchowicz G, Ganon L, Holtzman EJ: Molecular study of proteinuria in patients treated with $B 12$ supplements: do not forget megaloblastic anemia type 1. Nephron Clin Pract 2011, 118:c67-c71.

39. Kristiansen M, Aminoff M, Jacobsen C, de la Chapelle A, Krahe R, Verroust PJ, Moestrup SK: Cubilin P1297L mutation associated with hereditary megaloblastic anemia 1 causes impaired recognition of intrinsic factor-vitamin B(12) by cubilin. Blood 2000, 96:405-409.

40. Wahlstedt-Froberg V, Pettersson T, Aminoff M, Dugue B, Grasbeck R: Proteinuria in cubilin-deficient patients with selective vitamin B12 malabsorption. Pediatr Nephrol 2003, 18:417-421.

41. Chiu J, Tillett D, Dawes IW, March PE: Site-directed, Ligase-Independent Mutagenesis (SLIM) for highly efficient mutagenesis of plasmids greater than $8 \mathrm{~kb}$. J Microbiol Methods 2008, 73:195-198.

42. Adzhubei IA, Schmidt S, Peshkin L, Ramensky VE, Gerasimova A, Bork P, Kondrashov AS, Sunyaev SR: A method and server for predicting damaging missense mutations. Nat Methods 2010, 7:248-249.

43. Humphrey W, Dalke A, Schulten K: VMD: visual molecular dynamics. J Mol Graph 1996, 14:33-38.

44. Enders AC, Carter AM: Comparative placentation: some interesting modifications for histotrophic nutrition - a review. Placenta 2006, 27(Suppl A):S11-S16.

45. Zohn IE, Sarkar AA: The visceral yolk sac endoderm provides for absorption of nutrients to the embryo during neurulation. Birth Defects Res A Clin Mol Teratol 2010, 88:593-600.

46. Beech CM, Liyanarachchi S, Shah NP, Sturm AC, Sadiq MF, de la Chapelle A, Tanner SM: Ancient founder mutation is responsible for Imerslund-Grasbeck syndrome among diverse ethnicities. Orphanet J Rare Dis 2011, 6:74.

47. Luder AS, Tanner SM, de la CA, Walter JH: Amnionless (AMN) mutations in Imerslund-Grasbeck syndrome may be associated with disturbed vitamin B(12) transport into the CNS. J Inherit Metab Dis 2008. Epub ahead of print

48. Tanner S, Sturm A, Baack E, Liyanarachchi S, de la Chapelle A: Inherited cobalamin malabsorption. Mutations in three genes reveal functional and ethnic patterns. Orphanet J Rare Dis 2012, 7:56.

49. Ovunc B, Otto EA, Vega-Warner V, Saisawat P, Ashraf S, Ramaswami G, Fathy HM, Schoeb D, Chernin G, Lyons RH, et al: Exome sequencing reveals cubilin mutation as a single-gene cause of proteinuria. J Am Soc Nephrol 2011, 22:1815-1820

50. Fyfe JC, Hemker SL, Venta PJ, Fitzgerald CA, Outerbridge CA, Myers SL, Giger U: An exon 53 frameshift mutation in CUBN abrogates cubam function and causes Imerslund-Grasbeck syndrome in dogs. Mol Genet Metab 2013, 109:390-396.

51. Ahuja R, Yammani R, Bauer JA, Kalra S, Seetharam S, Seetharam B: Interactions of cubilin with megalin and the product of the amnionless gene (AMN): effect on its stability. Biochem J 2008, 410:301-308.

52. Christensen El, Birn H, Storm T, Weyer K, Nielsen R: Endocytic receptors in the renal proximal tubule. Physiology 2012, 27:223-236.

doi:10.1186/1471-2350-14-111

Cite this article as: Storm et al.: Detailed investigations of proximal tubular function in Imerslund-Gräsbeck syndrome. BMC Medical Genetics 2013 14:111.

\section{Submit your next manuscript to BioMed Central and take full advantage of:}

- Convenient online submission

- Thorough peer review

- No space constraints or color figure charges

- Immediate publication on acceptance

- Inclusion in PubMed, CAS, Scopus and Google Scholar

- Research which is freely available for redistribution

Submit your manuscript at www.biomedcentral.com/submit
() Biomed Central 